\title{
Adsorptive Removal of As(V) from Aqueous Solution onto Steel Slag Recovered Iron - Chitosan Composite: Response Surface Modeling and Kinetics
}

\author{
Vijayanand Nagarajan" ${ }^{*}$, Raja Ganesan', Srinivasan Govindan², Prabha Govindaraj³ \\ 1 Department of Chemistry, Paavai Engineering College (Autonomous), Anna University, NH-44 Paavai Nagar, 637018 Namakkal, \\ Tamil Nadu, India \\ 2 Department of Chemical Engineering, Paavai Engineering College (Autonomous), Anna University, NH-44 Paavai Nagar, \\ 637018 Namakkal, Tamil Nadu, India \\ 3 Department of Applied Science and Technology, Alagappa College of Technology, Anna University, Kotturpuram, \\ 600025 Chennai, Tamil Nadu, India \\ *Corresponding author, e-mail: vijayanandnagarajanpec@paavai.edu.in
}

Received: 17 September 2020, Accepted: 05 October 2020, Published online: 15 January 2021

\begin{abstract}
In the present work iron particles was recovered by dry magnetic separation, from waste steel slag, doped with chitosan for adsorbent prepared, characterized and evaluated for the removal of $\mathrm{As}(\mathrm{V})$ from an aqueous solution. The adsorption of $\mathrm{As}(\mathrm{V})$ was optimized by using response surface methodology through Box-Behnken design model, which gave high correlation coefficient $\left(R^{2}=0.9175\right)$, and a predictive model of quadratic polynomial equation. Analysis of variance and Fischer's F-test were used to govern the parameters which interrupt the adsorption of As(V).The adsorbent was characterized by FTIR, XRD and SEM. Optimal conditions, including adsorbent dosage, $\mathrm{pH}$, temperature, initial ion concentration and contact time for the removal of $\mathrm{As}(\mathrm{V})$, were found to be $0.8 \mathrm{~g}$, $\mathrm{pH} 4$, $308 \mathrm{~K}, 10 \mathrm{mg} \mathrm{L}^{-1}$ and $3 \mathrm{~h}$, respectively. Langmuir isotherm model fitted better compared to the Freundlich model having a maximum adsorption capacity of $11.76 \mathrm{mg} \mathrm{g}^{-1}$, a high regression coefficient value of 0.993 and least chi-square value of 0.1959 . The process was found to follow monolayer adsorption and pseudo-second-order kinetics. Thermodynamic parameters such as $\Delta S, \Delta H$ and $\Delta G$ indicated the feasibility, spontaneous and endothermic nature of adsorption. Successful regeneration of the adsorbent implies its applicability to the removal of arsenic from real life wastewater.
\end{abstract}

Keywords

arsenic, steel slag, chitosan, thermodynamic, response surface methodology

\section{Introduction}

Arsenic is a pervasive element in the environment and has been known as a notorious toxic substance to man and living organisms for centuries [1]. Groundwater arsenic is primarily associated with oxidative weathering and geochemical reactions. Carbon plays a major role in the mobilization of arsenic in the sediments [2]. Over 100 million people in Bangladesh, West Bengal, China, Mexico, Chile, Myanmar, and United states [3] were affected by the arsenic contaminated water. Long term exposure to arsenic in drinking water causes skin diseases (pigmentation, dermal hyperkeratosis, and skin cancer), cardiovascular, neurological, liver, kidney, and prostate cancers [4]. To protect public health, the World Health Organization has set a provisional guideline limit of $10 \mu \mathrm{g} \mathrm{L}^{-1}$ for arsenic [5] in drinking water. The removal of arsenic by various methods has been widely reviewed [6] Co-precipitation, flotation, ion-exchange, ultra-filtration, and reverse osmosis have been received more attention due to its high concentration efficiency. Several adsorbents have been found suitable for arsenic removal counting activated carbon [7], activated alumina [8], red mud [9], etc. In the last decade developments in the knowledge of biosorption exposed high adsorption capacities, low costs and regenerability of natural biosorption materials [10]. However, challenges encountered for biosorbents with high uptake, low cost and as well as in understanding the mechanism of biosorption with heavy metals. Chitin, a major component of crustacean shell and fungal biomass, on N-deacetylation produced chitosan. Chitin availed enormously from seafood 
processing wastes. Chitosan has been found to have good sorption capacity for many heavy metal ions, owing to its high amino content [11], through complexation with the amine groups present. The fact of a high attractiveness exist between inorganic arsenic species and iron advanced to develop Fe (III) bearing materials like goethite and hematite [12], ferrihydrite [13], and iron-doped activated carbons [14] for arsenic adsorption. Studies also recognized the applicability of chitosan-Fe nanoparticles for the removal of hexavalent chromium. Therefore, iron-doped chitosan nanoparticles should be a capable biosorbent for removing heavy metals, due to the presence of the amine and hydroxyl groups. In this study, a novel iron doped chitosan composite was prepared through a simple co-precipitation method, their performance was characterized and the sorption, isotherms, kinetics and thermodynamic property for removing arsenic from aqueous solution were investigated.

\section{Materials and methods}

\subsection{Materials}

Samples of desulfurized (De-S) fresh slag fines are collected from Steel Authority of India Limited (SAIL) Salem steel plant, chemical compositions of these slag fines are presented in Table 1. Chitosan (CS, MW $=2.65 \times 10^{5} \mathrm{Da}$ ) with $>80 \%$ deacetylation degree, Sodium hydrogen arsenate $\left(\mathrm{Na}_{2} \mathrm{HAsO}_{4} \cdot 7 \mathrm{H}_{2} \mathrm{O}\right)$, Sodium hydroxide and acetic acid were of analytical grade, acquired from Sigma Aldrich. Stock As(V) solution (1000 mg L $\mathrm{L}^{-1}$ ) was prepared from sodium hydrogen arsenate. All the reagents and glassware were prepared and rinsed with double de-ionized water.

\subsection{Magnetic separation of iron with a pilot magnetic}

\subsubsection{Drum separator}

Slag fines of $<10 \mathrm{~mm}$ size have been grinded by Soft Grinding (SG) methods for $30 \mathrm{~min}$ to recover fine particles of $<1 \mathrm{~mm}$ size. The SG mode has an advantage, over Classic Ball Grinding (CBG), by avoiding overproduction of fine particles which hamper the effectiveness of physical dry separation techniques. Dry magnetic drum separator, in Fig. 1, illustrates its working principle [15], which has a fixed permanent magnet cluster, a revolving nonmagnetic shell, and a splitter underneath the drum. On feeding the steelmaking slag particles into separator, the revolving shell brings the slag fines towards the drum bottom. More-magnetic particles gathered on the surface of the shell and fall onto the more magnetic product pile, while less-magnetic particles are thrown away from the drum surface and fall onto the less-magnetic product split. The separation can be further tuned by changing the splitter positions either towards drum surface for higher iron grade or away from the drum for higher yield of the more-magnetic product. The operating features of the drum are rotation at a constant speed of $36 \mathrm{rpm}$, field strength of 1650 gauss, drum radius of $400 \mathrm{~mm}$, drum flesh thickness of $2 \mathrm{~mm}$ and splitter gap of 25 to $35 \mathrm{~mm}$. The pilot magnetic drum separator used in this experimental work has the full features of an industrial magnetic drum separator [16].

\subsection{Preparation of iron doped chitosan composite}

Briefly, the synthesis procedure is as follows, the $\mathrm{FeO}$ particles $(0.15 \mathrm{~g})$ were dispersed in $2 \%(\mathrm{v} / \mathrm{v})$ acetic acid

Table 1 Chemical compositions of raw steel making slag fines (dry basis), wt $\%$

\begin{tabular}{lccccccccccccccc}
\hline Slag type & Sample & $\mathrm{MFe}$ & $\mathrm{TFe}$ & $\mathrm{SiO}_{2}$ & $\mathrm{Al}_{2} \mathrm{O}_{3}$ & $\mathrm{CaO}$ & $\mathrm{MgO}$ & $\mathrm{MnO}^{2}$ & $\mathrm{P}_{2}$ & $\mathrm{C}$ \\
\hline De-S & De-S1 & 12.34 & 34.51 & 9.19 & 2.16 & 29.86 & 5.21 & 1.89 & 0.18 & 0.14 & 3.32 & 0.561 \\
& De-S2 & 15.21 & 36.48 & 9.16 & 2.31 & 25.56 & 5.41 & 1.15 & 0.12 & 0.11 & 3.56 & 0.527 \\
\hline
\end{tabular}
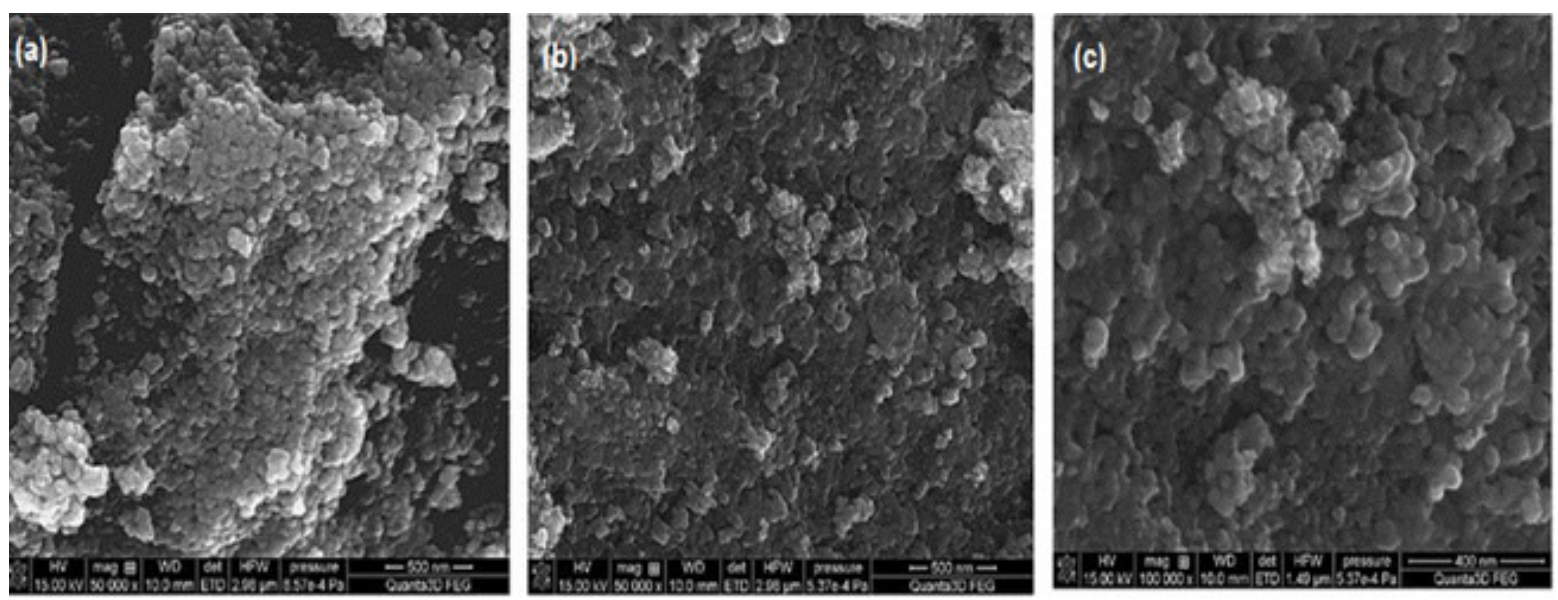

Fig. 1 SEM images of (a) pure chitosan (b) before As(V) adsorption (c) after As(V) adsorption of composite 
solution $(100 \mathrm{~mL})$. The chitosan $(1 \mathrm{~g})$ was then added, and the mixture was agitated for $60 \mathrm{~min}$, to reduce the agglomeration, followed by stirring. The subsequent precipitate obtained by adding $1 \mathrm{M} \mathrm{NaOH}$, was heated at $75^{\circ} \mathrm{C}$ for $4 \mathrm{~h}$, filtered, washed with deionized water, and finally dried in a vacuum oven at $40{ }^{\circ} \mathrm{C}$.

\subsection{Batch adsorption experiments}

Batch experiments were carried out in $100 \mathrm{~mL}$ polyethylene bottles with $50 \mathrm{~mL}$ of As solution having an initial concentration of $10 \mathrm{mg} \mathrm{L}^{-1}$. The investigation carries the effect of various parameters such as temperature $(293 \mathrm{~K}-313 \mathrm{~K}), \mathrm{pH}(2-10)$, reaction time $(5 \mathrm{~min}-5 \mathrm{~h})$, and adsorbent dosage $(0.1-2 \mathrm{~g} / 50 \mathrm{ml})$ in order to find the maximum uptake of arsenic ions. Samples were collected at fixed intervals and the adsorbent was removed by centrifugation at $6000 \mathrm{rpm}$ for $6 \mathrm{~min}$. The supernatant was analyzed for As(V) removal by AAS. Blanks were used for control in all the experiments. The amount of arsenic adsorbed $\left(\mathrm{mg} \mathrm{g}^{-1}\right)$ was determined by using the Eq. (1):

$q_{e}=\left(C_{o}-C_{e}\right) \times v / m$,

where $C_{o}$ and $C_{e}$ are the initial and equilibrium concentrations of the metal ion $\left(\mathrm{mg} \mathrm{L}^{-1}\right), m$ is the dry mass of irondoped chitosan $(g)$ and $v$ is the volume of the solution $(L)$. The \% removal of $\mathrm{As}(\mathrm{V})$ from aqueous solution was calculated by using Eq. (2):

$\operatorname{Removal}(\%)=\left[\left(C_{o}-C_{e}\right) / C_{o}\right] \times 100$.

\subsection{Design of experiments}

The adsorption of As( $\mathrm{V})$ process using the composite was demonstrated and optimized by a Box-Behnken Method (BBM) experimental design in RSM. For data analysis, design expert software (Stat Ease, Inc., Trial version 11, USA) was used. Batch experiments were performed based on BBM to investigate the effect of all four parameters. Equation (3) explains the coded values of the process variables:

$$
X_{i}=\frac{\left(x_{i}-x_{o i}\right)}{\Delta x_{i}}, \quad i=1,2,3 \ldots \ldots \ldots . . . k,
$$

where $X_{i}$ and $x_{i}$ are the coded and uncoded values of the $i^{\text {th }}$ variables, $x_{o i}$ denotes the uncoded values of the $i^{\text {th }}$ variable at the center point, and $\Delta x_{i}$ is the step change value. The levels of various parameters used in BBM design are represented in Table 2 .
Table 2 Factors and level of various parameters of BBM design for $\mathrm{As}(\mathrm{V})$ adsorption

\begin{tabular}{lcccc}
\hline & \multicolumn{4}{c}{ Level of factors } \\
Variables & Code & -1 & 0 & 1 \\
\hline Temperature $(\mathrm{K})$ & $x_{1}$ & 303 & 308 & 313 \\
$\mathrm{pH}$ & $x_{2}$ & 3 & 4 & 5 \\
Contact time (min) & $x_{3}$ & 120 & 180 & 240 \\
Adsorbent dosage $\left(\mathrm{mg} \mathrm{L}^{-1}\right)$ & $x_{4}$ & 600 & 700 & 800 \\
\hline
\end{tabular}

The \% removal of As(V) was determined by the following second order polynomial equation (Eq. (4)):

$$
Y=\beta_{0}+\sum_{i=0}^{4} \beta_{i} x_{i}+\sum_{i=0}^{4} \beta_{i i} x_{i}^{2}+\sum_{i, j=1(i \neq j)}^{4} \beta_{i j} x_{i} x_{j}+\varepsilon,
$$

where $Y$ is the response variable, $\beta_{o}, \beta_{i}, \beta_{i j}$ and $\beta_{i i}$ are the regression coefficients for intercept, linear effect, double interaction, and quadratic effects, respectively, $x_{i}, x_{j}$ are the independent variables, and $\varepsilon$ is a random error. Statistical analysis system and Tera plot software were used for the study of Analysis of variance (ANOVA), response surface studies and 3D surface plot generation respectively.

\subsection{Analytical measurements}

Fourier transform infrared spectra (FT-IR) and SEM analysis of the adsorbent recorded before and after $\mathrm{As}(\mathrm{V})$ adsorption with $\mathrm{KBr}$ discs in the range of 500-4000 $\mathrm{cm}^{-1}$ by Jasco-4200 and JOEL JSM-6360 scanning electron microscope at $15 \mathrm{kv}$ respectively. A Shimadzu AA 7000 model Atomic Absorption Spectrometer (AAS) was used to measure the concentration of adsorbed arsenic at $194 \mathrm{~nm}$ with an air-acetylene flame type.

\section{Results and discussion}

\subsection{Instrumental analysis}

Morphology study, (Fig. 1 (a), (b) and (c)), shows that the adsorbent is porous in nature and entitles good complexes with adsorbed arsenic ions. XRD diffraction peaks in Fig. 2 (a), of the composite, are found consistent with the standard XRD pattern of cubic FeO (JCPDS, no.65-3107) with Fig. 2 (b).The IR spectrum peak at $3450 \mathrm{~cm}^{-1}$ of pure chitosan (Fig. 2 (a) confirms the primary alcoholic group [17], and peak at $588 \mathrm{~cm}^{-1}$ (Fig. 2 (b)) of Fe-O group [18] presence. After As(V) adsorption (Fig. 2 (c)), the peak shift from 1655 to $1642 \mathrm{~cm}^{-1}$, new bands at $1560 \mathrm{~cm}^{-1}$ and $834 \mathrm{~cm}^{-1}$ predicts the amine dislodgement [19], nitrogen atom responsibility, and the existence of $\mathrm{As}(\mathrm{V})[20]$ in the adsorbent respectively. 


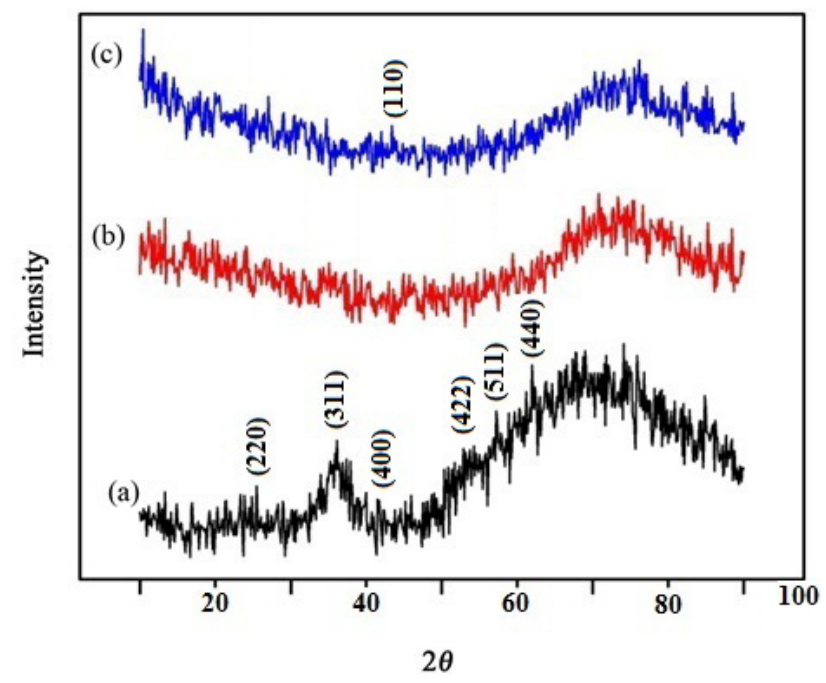

Fig. 2 XRD patterns of (a) FeO-Chitosan composite (b) FeO only (c) $\mathrm{As}(\mathrm{V})$ adsorbed FeO-Chitosan composite

\subsection{Quadratic model for $\mathrm{As}(\mathrm{V})$ adsorption}

The adsorbent $\mathrm{As}(\mathrm{V})$ removal capacity was optimized by employing the BBM technique. Table 3, display the 29 runs of experimental designs, along with corresponding adsorption results. The removal efficiency as functions of temperature $\left(x_{1}\right), \mathrm{pH}\left(x_{2}\right)$, reaction time $\left(x_{3}\right)$ and adsorbent dosage $\left(x_{4}\right)$ was correlated with the developed second-order polynomial equation given in Eq. (5):

$\%$ removal of As $(\mathrm{V})=-276.05000+13.506677 x_{1}$

$+11.55000 x_{2}+8.6667 x_{3}+0.213333 x_{4}+0.190000 x_{1} x_{2}$

$-0.090000 x_{1} x_{3}-0.003150 x_{1} x_{4}+0.450000 x_{2} x_{3}$

$+0.005000 x_{2} x_{4}-0.000250 x_{3} x_{4}-0.159167 x_{1}^{2}$

$-2.79167 x_{2}^{2}-1.15417 x_{3}^{2}-0.000074 x_{4}^{2}$.

The effect of independent variables on the adsorption efficiency of $\mathrm{As}(\mathrm{V})$ was described by the above equation predicts a maximum As(V) removal of $92 \%$.

Experimental curve fitting was evaluated to govern the significant model for this system (Table 4). Each type of model was calculated for Fischer $F$-test value. In general, larger $F$ - and lower probability values ( $p$-values) with significant terms were chosen. From the data given in Table 4, a quadratic model was suggested for higher $F$-value (23.49) and lower $p$-value $(<0.0001)$ with significant terms for this experimental design on compared with other models. The cubic model was found to be insignificant.

ANOVA justifies the significance of the quadratic model by correlating the model with the response variables. Table 5, shows the variables denoted in ANOVA was the main effects, the interaction effects, and the error terms.
Table 3 Experimental design with adsorption results

\begin{tabular}{|c|c|c|c|c|c|c|}
\hline \multicolumn{7}{|c|}{ Coded levels } \\
\hline Std & Run & $\begin{array}{c}\mathrm{A}: \\
x_{1}(\mathrm{k}) \\
\end{array}$ & $\begin{array}{l}\mathrm{B}: \\
x_{2} \\
\end{array}$ & $\begin{array}{c}\mathrm{C}: \\
x_{3}(\mathrm{~h}) \\
\end{array}$ & $\begin{array}{c}\mathrm{D}: \\
x_{4}\left(\mathrm{mg} \mathrm{L}^{-1}\right) \\
\end{array}$ & $\begin{array}{r}\text { Removal } \\
\text { of } \mathrm{As}(\mathrm{V}) \% \\
\end{array}$ \\
\hline 4 & 1 & 313 & 5 & 3 & 800 & 89.7 \\
\hline 16 & 2 & 308 & 5 & 4 & 800 & 90.1 \\
\hline 8 & 3 & 308 & 4 & 4 & 900 & 89.8 \\
\hline 12 & 4 & 313 & 4 & 3 & 900 & 88.8 \\
\hline 27 & 5 & 308 & 4 & 3 & 700 & 91.3 \\
\hline 23 & 6 & 308 & 3 & 3 & 900 & 85.5 \\
\hline 7 & 7 & 308 & 4 & 2 & 900 & 91.1 \\
\hline 9 & 8 & 303 & 4 & 3 & 700 & 82.9 \\
\hline 6 & 9 & 308 & 4 & 4 & 700 & 89.6 \\
\hline 13 & 10 & 308 & 3 & 2 & 800 & 87.2 \\
\hline 21 & 11 & 308 & 3 & 3 & 700 & 86.1 \\
\hline 15 & 12 & 308 & 3 & 4 & 800 & 88.3 \\
\hline 24 & 13 & 308 & 5 & 3 & 900 & 89.9 \\
\hline 19 & 14 & 303 & 4 & 4 & 800 & 85.5 \\
\hline 1 & 15 & 303 & 3 & 3 & 800 & 83.1 \\
\hline 17 & 16 & 303 & 4 & 2 & 800 & 84.2 \\
\hline 22 & 17 & 308 & 5 & 3 & 700 & 88.5 \\
\hline 26 & 18 & 308 & 4 & 3 & 800 & 91.8 \\
\hline 11 & 19 & 303 & 4 & 3 & 900 & 87.6 \\
\hline 18 & 20 & 313 & 4 & 2 & 800 & 87.2 \\
\hline 5 & 21 & 308 & 4 & 2 & 700 & 90.8 \\
\hline 25 & 22 & 308 & 3 & 3 & 800 & 90.8 \\
\hline 14 & 23 & 308 & 5 & 2 & 800 & 87.2 \\
\hline 28 & 24 & 308 & 4 & 4 & 800 & 91.4 \\
\hline 29 & 25 & 308 & 4 & 3 & 900 & 91.6 \\
\hline 10 & 26 & 313 & 4 & 3 & 700 & 90.4 \\
\hline 20 & 27 & 313 & 4 & 4 & 800 & 86.7 \\
\hline 3 & 28 & 300 & 5 & 3 & 800 & 84.2 \\
\hline 2 & 29 & 313 & 3 & 3 & 800 & 84.8 \\
\hline
\end{tabular}

Table 4 Experimental curve fitting of optimization

\begin{tabular}{lcccccc}
\hline Source & $\begin{array}{c}\text { Sum of } \\
\text { Squares }\end{array}$ & DF & $\begin{array}{c}\text { Mean } \\
\text { Square }\end{array}$ & $F-$ & $\begin{array}{c}p \text {-value } \\
\text { Prob }>F\end{array}$ & Remarks \\
\hline $\begin{array}{l}\text { Linear vs } \\
\text { mean }\end{array}$ & 53.49 & 4 & 13.3 & 1.92 & 0.140 & - \\
$\begin{array}{l}\text { 2FI vs } \\
\text { linear }\end{array}$ & 16.16 & 6 & 2.69 & 0.32 & 0.917 & - \\
$\begin{array}{l}\text { Quadratic } \\
\text { vs 2FI }\end{array}$ & 131.55 & 4 & 32.8 & 23.4 & $<0.0001$ & Suggested \\
$\begin{array}{l}\text { Cubic vs } \\
\text { quadratic }\end{array}$ & 12.52 & 8 & 1.57 & 1.33 & 0.3752 & Aliased \\
\hline
\end{tabular}

The importance of these variables was represented by $F$ and $p$ values. In the quadratic model developed, the $F$-value of 10.26 indicated that the model was statistically significant and there is only a $0.01 \%$ chance that an $F$-value this large 
Table 5 Analysis of variance for the quadratic model by BBM optimization for $\mathrm{As}(\mathrm{V})$ adsorption

\begin{tabular}{|c|c|c|c|c|c|c|}
\hline Source & $\begin{array}{l}\text { Sum of } \\
\text { Squares }\end{array}$ & DF & $\begin{array}{l}\text { Mean } \\
\text { Square }\end{array}$ & $F$-value & $\begin{array}{l}p \text {-value } \\
\text { Prob }>F\end{array}$ & Remarks \\
\hline Model & 201.19 & 14 & 14.37 & 10.26 & $<0.0001$ & Sig* \\
\hline$x_{1}(\mathrm{k})$ & 33.67 & 1 & 33.67 & 24.05 & 0.0002 & Sig* \\
\hline$x_{2}$ & 17.76 & 1 & 17.76 & 12.69 & 0.0031 & Sig* \\
\hline$x_{3}(\min )$ & 0.4408 & 1 & 0.4408 & 0.3149 & 0.5836 & - \\
\hline$x_{4}\left(\mathrm{mg} \mathrm{L}^{-1}\right)$ & 1.61 & 1 & 1.61 & 1.15 & 0.3012 & - \\
\hline$x_{1} x_{2}$ & 3.61 & 1 & 3.61 & 2.58 & 0.1306 & - \\
\hline$x_{1} x_{3}$ & 0.8100 & 1 & 0.8100 & 0.5785 & 0.4595 & - \\
\hline$x_{1} x_{4}$ & 9.92 & 1 & 9.92 & 7.09 & 0.0186 & Sig* \\
\hline$x_{2} x_{3}$ & 0.8100 & 1 & 0.8100 & 0.5785 & 0.4595 & - \\
\hline$x_{2} x_{4}$ & 1.0000 & 1 & 1.0000 & 0.7143 & 0.4122 & - \\
\hline$x_{3} x_{4}$ & 0.0025 & 1 & 0.0025 & 0.0018 & 0.9669 & - \\
\hline$x_{1}^{2}$ & 102.71 & 1 & 102.71 & 73.36 & $<0.0001$ & Sig* \\
\hline$x_{2}^{2}$ & 50.55 & 1 & 50.55 & 36.11 & $<0.0001$ & Sig* \\
\hline$x_{3}^{2}$ & 8.64 & 1 & 8.64 & 6.17 & 0.0263 & Sig* \\
\hline$x_{4}^{2}$ & 3.57 & 1 & 3.57 & 2.55 & 0.1327 & - \\
\hline Residual & 19.60 & 14 & 1.40 & - & - & - \\
\hline Lack of fit & 19.60 & 10 & 1.96 & - & - & Not Sig\# \\
\hline Pure error & 0.0000 & 4 & 0.0000 & - & - & - \\
\hline Cor total & 220.79 & 28 & - & - & - & - \\
\hline
\end{tabular}

could occur due to noise. The model suggested was highly significant due to its $p$-value of $<0.0001$. The Table 5 shows the six significant terms with low $p$-values were $x_{1}, x_{2}, x_{1} x_{4}$, $x_{1}^{2}, x_{2}^{2}$ and $x_{3}^{2}$. Other significant terms were not discussed because of their high $p$-values. The above model accuracy could be assessed by the fortitude of regression coefficient $R^{2}$. The value of $R^{2}=0.9112$, in the present study, indicated that only $9 \%$ of the total variables were not explained by the model. The adjusted coefficient value $\left(R^{2} \mathrm{adj}=0.8225\right)$ was not in realistic arrangement with observed $R^{2}$. The model has undesirable lack of fit by the indication of lack of fit $p$-value ( $>0.05)$ suggested that it is not significantly relative to the pure error and, thus, above quadratic equation and the model were accurate for the experiment [21]. The value of signal to noise ratio was found to be 10.238 , ratio $>4$ is desirable, indicated an adequate signal to navigate the design space. The Fig. 3, of the graph, plotted between actual and predicted values for removal of $\mathrm{As}(\mathrm{V})$, indicated that the distribution of actual values were relatively close to the straight line which, specifies the quadratic model was necessary for predicting the efficient removal of $\mathrm{As}(\mathrm{V})$ under the parameters studied.

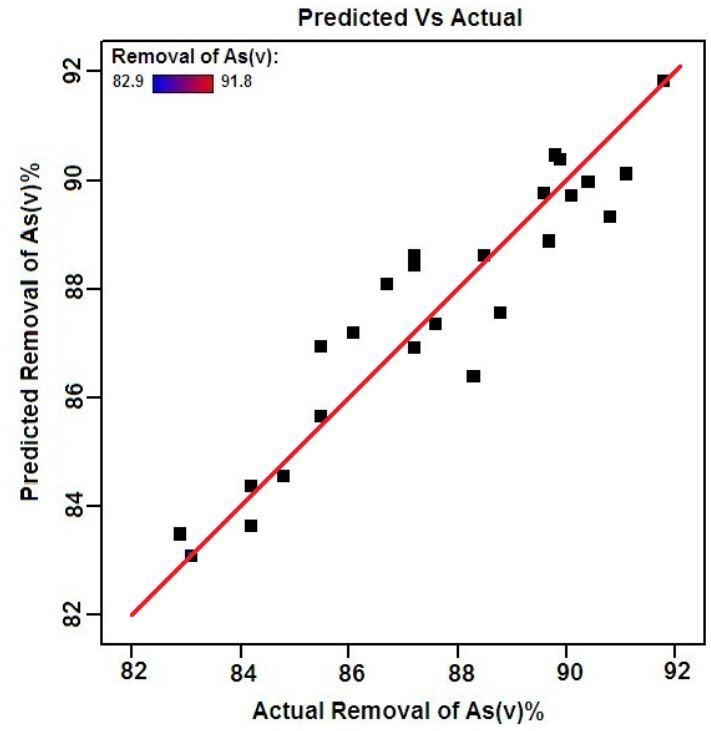

Fig. 3 Comparison between actual and predicted values of RSM model on optimized parameters for $\mathrm{As}(\mathrm{V})$ removal

The plot between studentized residuals and run number, in Fig. 4, showed that the random distribution of residuals around \pm 3.9 (limit is $< \pm 4.00$ ) [21] was a good sign of well fitted experimental data with the model.

\subsection{Effect of process variables on removal of $\mathrm{As}(\mathrm{V})$}

To optimize the process variables of equilibrium conditions, from batch experiments, it was necessary to study the impact of each variable on the adsorption process. Hence, three-dimensional curves were plotted between the variables of temperature, $\mathrm{pH}$, reaction time and adsorbent dosage. Fig. 5 (a), represents the effect of temperature and $\mathrm{pH}$ indicated that

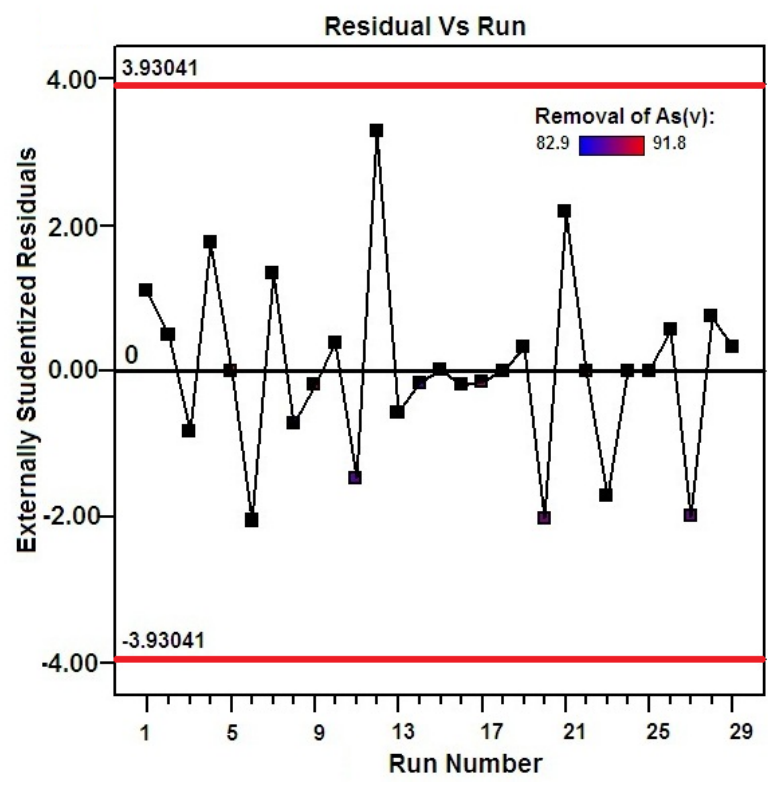

Fig. 4 Plot of studentized residuals versus experimental run number on optimized parameters for As(V) removal. 

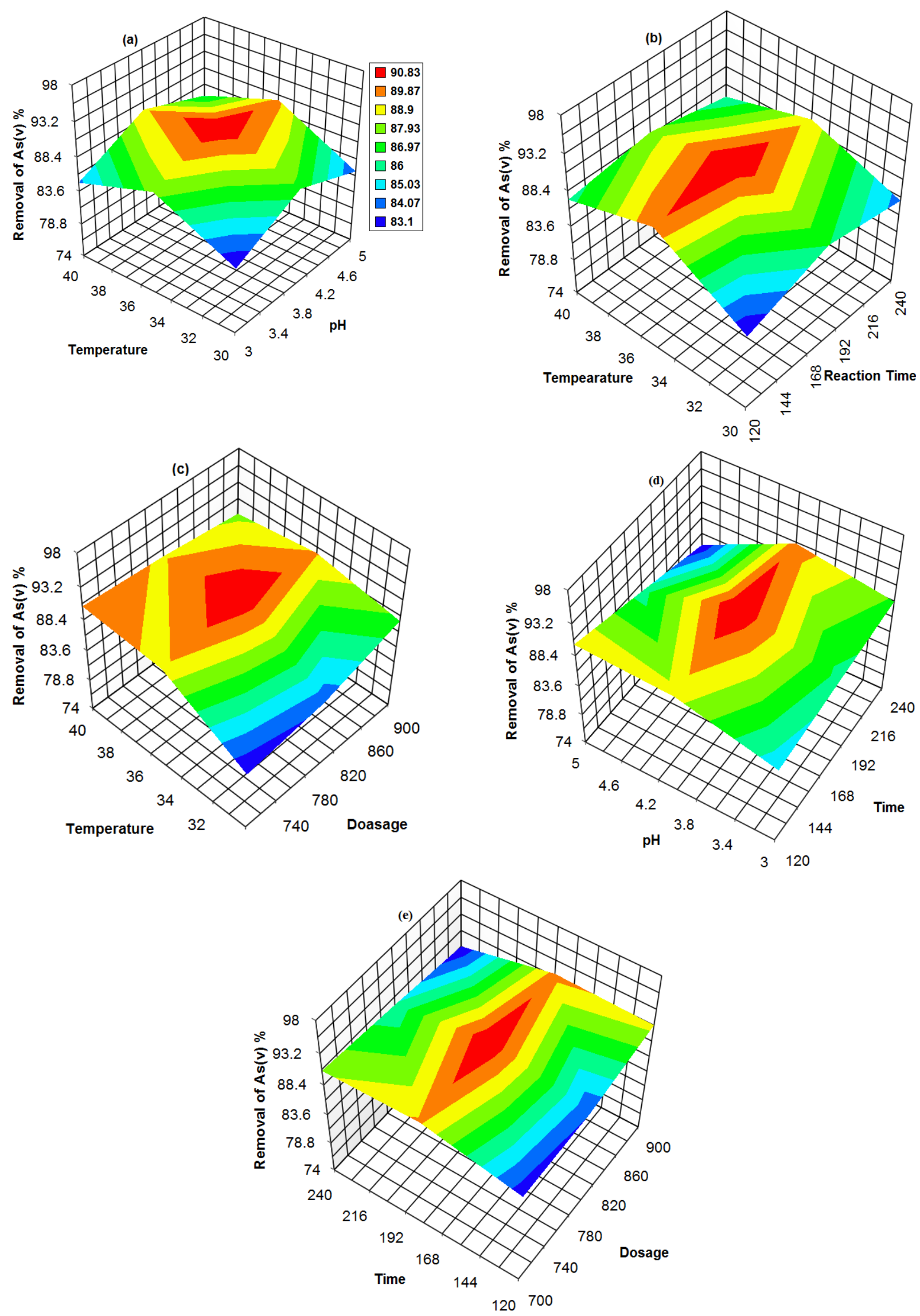

Fig. 5 3D surface mapping plot for multiple effects of (a) temperature and $\mathrm{pH}$ (b) temperature and time (c) dosage and temperature (d) time and $\mathrm{pH}$ (e) reaction time and adsorbent dosage on $\mathrm{As}(\mathrm{V})$ removal. 
the adsorption reaches maximum at $308 \mathrm{~K}$ on $\mathrm{pH} 4$ and then decreases, infers that the process is dependent on $\mathrm{pH}$ and temperature. It may due to desorption, at higher $\mathrm{pH}$ and temperature, the decreasing trend in adsorption continues.

The correlation of temperature and reaction time is as shown in Fig. 5 (b). The optimal adsorption efficiency of $91.8 \%$ was reached within $180 \mathrm{~min}$ at temperature of $308 \mathrm{~K}$. The observation found that as contact time $(>180 \mathrm{~min})$ and temperature $\left(>35^{\circ} \mathrm{C}\right)$ increased, the adsorption rate decreased.

The plot of temperature versus adsorbent dosage in Fig. 5 (c), shows that the degree of adsorption increases with increasing adsorbent dosage, up to $800 \mathrm{mg}$ on $308 \mathrm{~K}$, due to high surface availability. While beyond $800 \mathrm{mg}$ dosage and $308 \mathrm{~K}$ it has equilibrium and decreasing trend starts for the variables respectively infer, that the temperature plays a major role in the adsorption procedure.

Fig. 5 (d) shows the effect of time and $\mathrm{pH}$. The adsorption capacity was almost constant with respect to time in the $\mathrm{pH}$ range 3-3.7. When the $\mathrm{pH}$ was beyond 3.7 the adsorption increases and reaches maximum at $\mathrm{pH} 4$. The relation of reaction time and adsorption dosage plotted in Fig. 5 (e), fairly indicates that the adsorption rate is almost constant on increasing time and gradually increases with respect to dosage and reaches maximum adsorption level at $180 \mathrm{~min}$ and $800 \mathrm{mg}$ respectively.

From the above, process variable correlations studied, it was evident that the adsorption rate was remarkably affected by temperature and $\mathrm{pH}$, while the contact time and adsorbent dosage had fringe effect only. The above fact is supported by the contour plot, in Fig. 3, between $\mathrm{pH}$ and temperature which also shows that the experimental and predicted removal efficiency was $91.8 \%$ and $92 \%$ respectively with a difference of minimum $0.2 \%$ under the optimal conditions. By the observation, the adsorption is endothermic in nature and takes place by diffusion and complexation process [22] respectively. The increase in the adsorption capacity was due to both the increase of the diffusion rate of $\mathrm{As}(\mathrm{V})$ and the rate of complexation with the functional groups present in the adsorbent [23].

\subsection{Adsorption isotherms}

The isotherm equations could be used to describe the sorption data, sorption mechanism, the surface properties and the affinity between sorbent and sorbate. The various isotherms models employed in the linear form [24], equilibrium parameters, linear regression analysis, and computed constants were shown in Table 6.
Table 6 Comparison of equilibrium parameters at different temperature

\begin{tabular}{lcccc}
\hline \multirow{2}{*}{ Model } & Parameters & \multicolumn{3}{c}{ Temperature $(\mathrm{K})$} \\
& $K_{1}(\mathrm{~L} / \mathrm{mg})$ & 10.86 & 10.98 & 11.76 \\
& $q_{m}(\mathrm{mg} / \mathrm{g})$ & 0.0355 & 0.0440 & 0.0573 \\
Langmuir & $R^{2}$ & 0.981 & 0.985 & 0.993 \\
& $\mathrm{R}_{\mathrm{L}}$ & 0.7380 & 0.6944 & 0.6357 \\
& $\mathrm{RMSE}$ & 0.4999 & 0.4547 & 0.3284 \\
& $\chi^{2}$ & 0.3192 & 0.3754 & 0.1959 \\
\hline \multirow{3}{*}{ Freundlich } & $K_{F}(\mathrm{mg} / \mathrm{g})$ & 0.7298 & 0.7953 & 0.9231 \\
& $\eta$ & 1.4684 & 1.6583 & 1.6694 \\
& $R^{2}$ & 0.897 & 0.982 & 0.985 \\
& $\mathrm{RMSE}$ & 3.8007 & 4.3404 & 4.7157 \\
& $\chi^{2}$ & 13.827 & 15.64 & 16.8591 \\
\hline
\end{tabular}

\subsubsection{Langmuir isotherms}

The linear form of the isotherm can be explained by Eq. (6) represents monolayer sorption:

$\frac{C_{e}}{q_{e}}=\frac{1}{K_{1} q_{m}}+\frac{C_{e}}{q_{m}}$.

The maximum adsorption capacity, $q_{m}=10.86-$ $11.76 \mathrm{mg} \mathrm{g}^{-1}$, and higher regression coefficient, $R^{2}=0.993$ were obtained from the Langmuir isotherm plots (Fig. 6), suggesting that the surface was homogenous. The dimensionless factor $\left(\mathrm{R}_{\mathrm{L}}=1 / 1+b C_{o}\right)$ was calculated as $<1$, indicates favorable adsorption and follows monolayer process [25]. The certainty of the isotherm was committed by the least RMSE and $\chi^{2}$ values than other isotherm model employed.

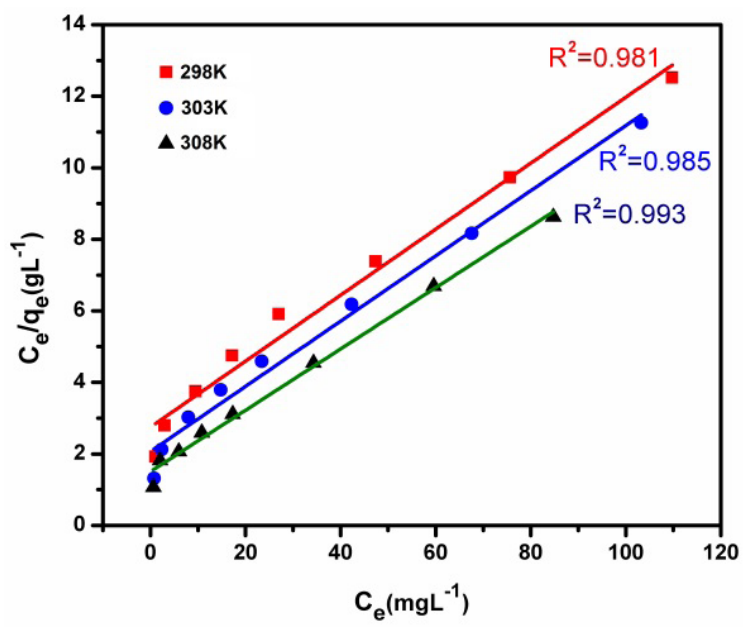

Fig. 6 Langmuir isotherm plot for the adsorption of As(V) ion by composite adsorbent. at different temperatures 


\subsubsection{Freundlich isotherm}

The isotherm is employed by Eq. (7):

$\log q_{e}=\log K_{F}+\frac{1}{n} \log C_{e}$,

which describes the sorption on an energetically heterogeneous surface and the distribution of active sites and their energies [26]. The value of $n$ (intensity) obtained, from the Freundlich model (Fig. 4), in the range 1-10 signifies the good performance of $\mathrm{FeO}$ doped chitosan adsorbent towards $\mathrm{As}(\mathrm{V})$ adsorption.

\subsection{Residual Mean Square Error (RMSE) analysis}

The $R^{2}$ values does not represent the errors in the isotherm curves. To evaluate the fit of the isotherm equations, the RMSE [27] analysis is employed.

$\mathrm{RMSE}=\sqrt{\frac{1}{n-2} \sum_{i=1}^{n}\left(q_{e, \text { exp }}-q_{e, \text { cal }}\right)^{2}}$

$q_{e, \text { exp }}, q_{e, c a l}$ and $n$ are the experimental, calculated values and number of observations respectively. The smaller the RMSE value the better the curve fitting. From Table 7, it assures that the process best fit was affirmed for Langmuir model.

\subsection{Chi-square $\left(\chi^{2}\right)$ statistical test}

The $\chi^{2}$ test confirms the suitability of a particular isotherm model [28], in describing the experimental data. Equation (9) is given as:

$\chi^{2}=\sum \frac{\left(q_{e, e x p}-q_{e, c a l}\right)^{2}}{q_{e, c a l}}$.

The $\chi^{2}$ value would be less if the adsorption data correlated concurs with experimental values. By which, from Table 7, the adsorption suitability more correlate with the Langmuir model than other models.

\subsection{Adsorption kinetics modeling}

\subsubsection{First order and pseudo-second-order kinetics}

Kinetics study revealed the information on the solute uptake and the reaction pathways. It was evaluated using the First order and pseudo-second order equations. The pseudo-first-order linear equation elucidate mechanism of adsorption and rate controlling steps [29], explained by Eq. (10):

$\log \left(q_{e}-q_{t}\right)=\log q_{e}-\frac{K_{1} t}{2.303}$

However, a pseudo-second-order equation analyzed the effective adsorption capacity, initial adsorption rate and rate limiting step [30]. The linear form of pseudo-second-order equation can be represented as follows (Eq. (11)):

$$
\frac{t}{q_{t}}=\frac{t}{k_{2} q_{e}^{2}}+\frac{t}{q_{e}} \text {. }
$$

The initial adsorption rate, $h\left(\mathrm{mg} \mathrm{g}^{-1} \mathrm{~min}^{-1}\right)$, as $t \rightarrow 0$, can be defined by the Eq. (12):

$h=k_{2} q_{e}^{2}$.

The kinetic parameters were obtained through the Pseudo first order plot (Fig. 5) and second order plot (Fig. 7), presented in Table 7.

Table 7 shows a higher regression coefficient and $h$ values of 0.994 and 0.0878 respectively, obtained from the Pseudo second order model, exposed its applicability,

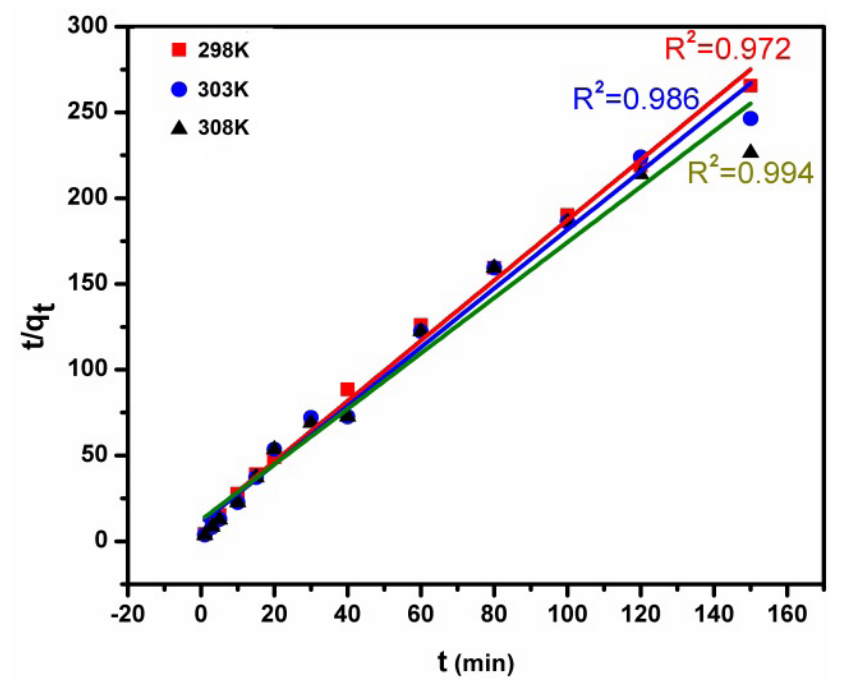

Fig. 7 Pseudo-second-order kinetics plot for the adsorption of $\mathrm{As}(\mathrm{V})$ ion at different temperatures

Table 7 Kinetic parameters of As(V) adsorption at different temperatures

\begin{tabular}{|c|c|c|c|c|c|c|c|c|}
\hline \multirow[b]{2}{*}{$\begin{array}{l}\text { Temp } \\
(\mathrm{K})\end{array}$} & \multirow[b]{2}{*}{$\begin{array}{c}q_{e, \exp } \\
(\mathrm{mg} / \mathrm{g})\end{array}$} & \multicolumn{3}{|c|}{ Pseudo first order } & \multicolumn{4}{|c|}{ Pseudo Second order } \\
\hline & & $\begin{array}{c}q_{e, c a l} \\
(\mathrm{mg} / \mathrm{g})\end{array}$ & $k_{2} / \min$ & $R^{2}$ & $\begin{array}{c}h \\
(\mathrm{mg} /(\mathrm{g} \min ))\end{array}$ & $\begin{array}{c}q_{e, c a l} \\
(\mathrm{mg} / \mathrm{g})\end{array}$ & $k_{2} / \min$ & $R^{2}$ \\
\hline 298 & 0.5578 & 0.5359 & 0.0133 & 0.968 & 0.0758 & 0.5715 & 0.2326 & 0.972 \\
\hline 303 & 0.5775 & 0.5467 & 0.0148 & 0.973 & 0.0816 & 0.5792 & 0.2432 & 0.986 \\
\hline 308 & 0.5860 & 0.5575 & 0.1610 & 0.984 & 0.0878 & 0.5866 & 0.2549 & 0.994 \\
\hline
\end{tabular}


chemisorption and rate limiting step nature of reaction [31] in the adsorption process.

\subsection{Adsorption thermodynamics}

The thermodynamic parameters $\Delta G, \Delta H$, and $\Delta S$ were utilized to elucidate the feasibility of adsorption [32]. The Van't Hoff plot, Fig. 8, (ln $k_{c}$, equilibrium constant, against $1 / T$ ) relates the parameters can be explained by Eqs. (13) and (14):

$$
\begin{aligned}
& \ln k_{c}=\frac{-\Delta H}{R T}+\frac{\Delta S}{R}, \\
& \Delta G=-R T \ln k_{c} .
\end{aligned}
$$

The calculated values of the energy parameters $\Delta G$, $\Delta H$, and $\Delta S$ are given in the Table 8.

The negative $\Delta G$, free energy values, positive value of enthalpy, $\Delta H=6.0724\left(<80 \mathrm{~kJ} \mathrm{~mol}^{-1}\right)$ suggested the feasibility, spontaneous and endothermic process respectively [33]. The positive value of $\Delta S$, entropy, reflects the affinity and structural changes in adsorbent and adsorbate during adsorption process [34].

\section{Conclusions}

In this study, a novel iron doped chitosan biosorbent was prepared, characterized, evaluated, and successfully employed for arsenic removal. The main variables optimized by Box-Behnken Design of RSM model $\left(R^{2}=0.9112\right)$ were in good agreement with arsenic adsorption process. The maximum sorption capacity for $\operatorname{As}(\mathrm{V})$ was found to be $11.76 \mathrm{mg} \mathrm{g}^{-1}$ from the Langmuir isotherm and follows pseudo-second-order kinetics. Thermodynamic studies revealed the process is feasible, spontaneous, and endothermic in nature. Interfering ions had marginal effects on adsorption. Thus, it concluded the iron doped chitosan composite, from waste steel slag, would be a potential candidate for arsenic filtering units, due to its biocompatibility.

\section{References}

[1] Chappell, W. R., Abernathy, C. O., Calderon, R. L. "Preface", In: Arsenic Exposure and Health Effects III: Proceedings of the Third International Conference on Arsenic Exposure and Health Effects, San Diego, CA, USA, 1999, pp. vii-viii. https://doi.org/10.1016/b978-008043648-7/50001-7

[2] Chatterjee, S., De, S. "Adsorptive removal of arsenic from groundwater using chemically treated iron ore slime incorporated mixed matrix hollow fiber membrane", Separation and Purification Technology, 179, pp. 357-368, 2017.

https://doi.org/10.1016/j.seppur.2017.02.019

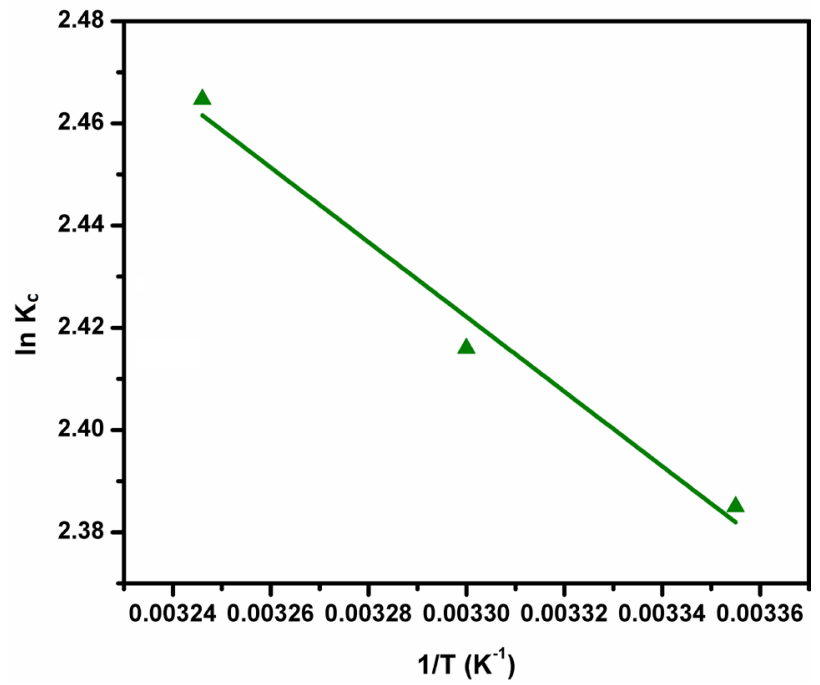

Fig. 8 Van't Hoff plot at different temperatures

Table 8 Thermodynamic parameters of As(V) adsorption at different temperatures

\begin{tabular}{lccc}
\hline \multicolumn{4}{c}{ Van't Hoff plot } \\
Temp $(\mathrm{K})$ & $\Delta G(\mathrm{~kJ} / \mathrm{mol})$ & $\Delta H(\mathrm{~kJ} / \mathrm{mol})$ & $\Delta S\left(\mathrm{~J} \mathrm{~mol}^{-1} \mathrm{~K}^{-1}\right)$ \\
\hline 298 & -5.9090 & 6.0742 & 0.04018 \\
303 & -6.0862 & & \\
308 & -6.3133 & & \\
\hline
\end{tabular}

\section{Acknowledgements}

The author would like to thank Department of Metallurgical Engineering, Government College of Engineering Salem and Indian Institute of Technology Madras for providing analytical instrumentation facility.

One of the authors Dr. G. Prabha would like to thank University Grant Commission (UGC), Government of India, for providing the fund under the scheme of UGC - Dr. D.S. Kothari Postdoctoral Fellowship (Award No:F.4-2/2006(BSR)/CH/18-19/0110).

[3] Jain, C. K., Singh, R. D. "Technological options for the removal of arsenic with special reference to South East Asia", Journal of Environmental Management, 107, pp. 1-18, 2012. https://doi.org/10.1016/j.jenvman.2012.04.016

[4] Shakoor, M. B., Nawaz, R., Hussain, F., Raza, M., Ali, S., Rizwan, M., Oh, S.-E., Ahmad, S. "Human health implications, risk assessment and remediation of As-contaminated water: A critical review", Science of the Total Environment, 601-602, pp. 756-769, 2017.

https://doi.org/10.1016/j.scitotenv.2017.05.223 
[5] World Health Organization "Guidelines for Drinking-water Quality", World Health Organization (WHO), Geneva, Switzerland, 2017. [online] Available at: https://www.who.int/ publications/i/item/9789241549950 [Accessed: 09 April 2019]

[6] Hao, L., Liu, M., Wang, N., Li, G. "A critical review on arsenic removal from water using iron-based adsorbents", RSC Advances, 8(69), pp. 39545-39560, 2018.

https://doi.org/10.1039/C8RA08512A

[7] Qi, J., Zhang, G., Li, H. "Efficient removal of arsenic from water using a granular adsorbent: Fe-Mn binary oxide impregnated chitosan bead", Bioresource Technology, 193, pp. 243-249, 2015. https://doi.org/10.1016/j.biortech.2015.06.102

[8] Zhou, Z., Liu, Y., Liu, S., Liu, H., Zeng, G., Tan, X., Yang, C., Ding, Y., Yan, Z., Cai, X. "Sorption performance and mechanisms of $\operatorname{arsenic}(\mathrm{V})$ removal by magnetic gelatin-modified biochar", Chemical Engineering Journal, 314, pp. 223-231, 2017. https://oi.org/10.1016/j.cej.2016.12.113

[9] Mahbubul Hassan, M., Davies-McConchie, J. F. "Removal of Arsenic and Heavy Metals From Potable Water by Bauxsol Immobilized onto Wool Fibers", Industrial and Engineering Chemistry Research, 51(28), pp. 9634-9641, 2012. https://doi.org/10.1021/ie300286k

[10] Saini, A. S., Melo, J. S. "Biosorption of uranium by melanin: Kinetic, equilibrium and thermodynamic studies", Bioresource Technology, 149, pp. 155-162, 2013. https://doi.org/10.1016/j.biortech.2013.09.034

[11] Gupta, A., Yunus, M., Sankararamakrishnan, N. "Chitosan- and Iron-Chitosan-Coated Sand Filters: A Cost-Effective Approach for Enhanced Arsenic Removal", Industrial and Engineering Chemistry Research, 52(5), pp. 2066-2072, 2013. https://doi.org/10.1021/ie302428z

[12] Futalan, C. M., Huang, Y.-S., Chen, J.-H., Wan, M.-W. "Arsenate removal from aqueous solution using chitosan-coated bentonite, chitosan-coated kaolinite and chitosan-coated sand: parametric, isotherm and thermodynamic studies", Water Science \& Technology, 78(3), pp. 676-689, 2018. https://doi.org/10.2166/wst.2018.339

[13] Hokkanen, S., Repo, E., Lou, S., Sillanpää, M. "Removal of arsenic(V) by magnetic nanoparticles activated micro fibrillated cellulose", Chemical Engineering Journal, 260, pp. 886-894, 2015. https://doi.org/10.1016/j.cej.2014.08.093

[14] Lunge, S., Singh, S., Sinha, A. "Magnetic iron oxide $\left(\mathrm{Fe}_{3} \mathrm{O}_{4}\right)$ nanoparticles from tea waste for arsenic removal", Journal of Magnetism Magnetic Materials, 356, pp. 21-31, 2014. https://doi.org/10.1016/j.jmmm.2013.12.008

[15] Ma, N., Houser, J. B., Wood, L. A., Lewis, R. W., Hill, D. G. "Enhancement of Iron Recovery from Steelmaking Slag Fines by Process Optimization of Upgrading the Slag Fines with Dry Magnetic Separation", Journal of Sustainable Metallurgy, 3(2), pp. 280-288, 2017. https://doi.org/10.1007/s40831-016-0079-z

[16] Menad, N., Kanari, N., Save, M. "Recovery of high grade iron compounds from LD slag by enhanced magnetic separation techniques", International Journal of Mineral Processing, 126, pp. 1-9, 2014.

https://doi.org/10.1016/j.minpro.2013.11.001
[17] Haldorai, Y., Rengaraj, A., Ryu, T., Shin, J., Huh, Y. S., Han, Y.-K. "Response surface methodology for the optimization of lanthanum removal from an aqueous solution using a $\mathrm{Fe}_{3} \mathrm{O}_{4}$ /chitosan nanocomposite", Materials Science and Engineering: B, 195, pp. 20-29, 2015. https://doi.org/10.1016/j.mseb.2015.01.006

[18] Siddiqui, S. I., Chaudhry, S. A. "Iron oxide and its modified forms as an adsorbent for arsenic removal: A comprehensive recent advancement", Process Safety and Environmental Protection, 111, pp. 592-626, 2017. https://doi.org/10.1016/j.psep.2017.08.009

[19] Malwal, D., Gopinath, P. "Silica Stabilized Magnetic-Chitosan Beads for Removal of Arsenic from Water", Colloid and Interface Science Communications, 19, pp. 14-19, 2017. https://doi.org/10.1016/j.colcom.2017.06.003

[20] Kumar, A. S. K., Jiang, S.-J. "Chitosan-functionalized graphene oxide: A novel adsorbent an efficient adsorption of arsenic from aqueous solution", Journal of Environmental Chemical Engineering, 4(2), pp. 1698-1713, 2016. https://doi.org/10.1016/j.jece.2016.02.035

[21] Sahu, U. K., Mahapatra, S. S., Patel, R. K. "Application of BoxBehnken Design in response surface methodology for adsorptive removal of arsenic from aqueous solution using $\mathrm{CeO}_{2} / \mathrm{Fe}_{2} \mathrm{O}_{3}$ / grapheme nanocomposite", Materials Chemistry Physics, 207, pp. 233-242, 2018.

https://doi.org/10.1016/j.matchemphys.2017.11.042

[22] Sharma, S., Bharathi, M., Rajesh, N. "Efficacy of a heterocyclic ligand anchored biopolymer adsorbent for the sequestration of palladium", Chemical Engineering Journal, 259, pp. 457-466, 2015. https://doi.org/10.1016/j.cej.2014.08.002

[23] Chio, C.-P., Lin, M.-C., Liao, C.-M. "Low-cost farmed shrimp shells could remove arsenic from solutions kinetically", Journal of Hazardous Materials, 171(1-3), pp. 859-864, 2009.

https://doi.org/10.1016/j.jhazmat.2009.06.086

[24] Ayawei, N., Ekubo, A. T., Wankasi, D., Dikio, E. D. "Adsorption of Congo Red by Ni/Al- $\mathrm{CO}_{3}$ : Equilibrium, Thermodynamic and Kinetic Studies", Oriental Journal of Chemistry, 31(3), pp. 1307-1318, 2015.

https://doi.org/10.13005/ojc/310307

[25] Hu, Q., Liu, Y., Gu, X., Zhao, Y. "Adsorption behavior and mechanism of different arsenic species on mesoporous $\mathrm{MnFe}_{2} \mathrm{O}_{4}$ magnetic nanoparticles", Chemosphere, 181, pp. 328-336, 2017. https://doi.org/10.1016/j.chemosphere.2017.04.049

[26] Jiang, Y., Gong, J.-L., Zeng, G.-M., Ou, X.-M., Chang, Y.-N., Deng, C.-H., Zhang, J., Liu, H.-Y., Huang, S.-Y. "Magnetic chitosan-graphene oxide composite for anti-microbial and dye removal applications", International Journal of Biological Macromolecules, 82, pp. 702-710, 2016. https://doi.org/10.1016/j.ijbiomac.2015.11.021

[27] Choudhary, B., Paul, D. "Isotherms, kinetics and thermodynamics of hexavalent chromium removal using biochar", Journal of Environmental Chemical Engineering, 6(2), pp. 2335-2343, 2018. https://doi.org/10.1016/j.jece.2018.03.028

[28] Saadi, R., Saadi, Z., Fazaeli, R., Fard, N. E. "Monolayer and multilayer adsorption isotherm models for sorption from aqueous media", Korean Journal of Chemical Engineering, 32(5), pp. 787-799, 2015. https://doi.org/10.1007/s11814-015-0053-7 
[29] Poinern, G. E. J., Parsonage, D., Issa, T. B., Ghosh, M. K., Paling, E., Singh, P. "Preparation, characterization and $\mathrm{As}(\mathrm{V})$ adsorption behavior of CNT-ferrihydrite composites", International Journal of Engineering, Science and Technology, 2(8), pp. 13-24, 2010. https://doi.org/10.4314/ijest.v2i8.63776

[30] Kumar, A. S. K., Kumar, C. U., Rajesh, V., Rajesh, N. "Microwave assisted preparation of $\mathrm{n}$-butylacrylate grafted chitosan and its application for $\mathrm{Cr}(\mathrm{VI})$ adsorption", International Journal of Biological Macromolecules, 66, pp. 135-143, 2014. https://doi.org/10.1016/j.ijbiomac.2014.02.007

[31] Gupta, A., Yunus, M., Sankararamakrishnan, N. "Zerovalent iron encapsulated chitosan nanospheres - A novel adsorbent for the removal of total inorganic Arsenic from aqueous systems", Chemosphere, 86(2), pp. 150-155, 2012.

https://doi.org/10.1016/j.chemosphere.2011.10.003
[32] Awwad, A. M., Salem, N. M. "Kinetics and thermodynamics of $\mathrm{Cd}(\mathrm{II})$ biosorption onto loquat (Eriobotrya japonica) leaves", Journal of Saudi Chemical Society, 18(5), pp. 486-493, 2014. https://doi.org/10.1016/j.jscs.2011.10.007

[33] Zhao, J., Wang, S., Zhang, L., Wang, C., Zhang, B. "Kinetic, Isotherm, and Thermodynamic Studies for $\mathrm{Ag}(\mathrm{I})$ Adsorption Using Carboxymethyl Functionalized Poly(glycidyl methacrylate)", Polymers, 10(10), Article number: 1090, 2018 https://doi.org/10.3390/polym10101090

[34] Guo, H., Stüben, D., Berner, Z. "Removal of arsenic from aqueous solution by natural siderite and hematite", Applied Geochemistry, 22(5), pp. 1039-1051, 2007.

https://doi.org/10.1016/j.apgeochem.2007.01.004 